\title{
Coefficient of restitution for particles impacting on wet surfaces: An improved experimental approach
}

\section{Citation for published version (APA):}

Crüger, B., Salikov, V., Heinrich, S., Antonyuk, S., Sutkar, V. S., Deen, N. G., \& Kuipers, J. A. M. (2016). Coefficient of restitution for particles impacting on wet surfaces: An improved experimental approach.

Particuology, 25, 1-9. https://doi.org/10.1016/j.partic.2015.04.002

\section{Document license: \\ TAVERNE}

DOI:

10.1016/j.partic.2015.04.002

Document status and date:

Published: 01/01/2016

\section{Document Version:}

Publisher's PDF, also known as Version of Record (includes final page, issue and volume numbers)

\section{Please check the document version of this publication:}

- A submitted manuscript is the version of the article upon submission and before peer-review. There can be important differences between the submitted version and the official published version of record. People interested in the research are advised to contact the author for the final version of the publication, or visit the $\mathrm{DOI}$ to the publisher's website.

- The final author version and the galley proof are versions of the publication after peer review.

- The final published version features the final layout of the paper including the volume, issue and page numbers.

Link to publication

\section{General rights}

Copyright and moral rights for the publications made accessible in the public portal are retained by the authors and/or other copyright owners and it is a condition of accessing publications that users recognise and abide by the legal requirements associated with these rights.

- Users may download and print one copy of any publication from the public portal for the purpose of private study or research.

- You may not further distribute the material or use it for any profit-making activity or commercial gain

- You may freely distribute the URL identifying the publication in the public portal.

If the publication is distributed under the terms of Article 25fa of the Dutch Copyright Act, indicated by the "Taverne" license above, please follow below link for the End User Agreement:

www.tue.nl/taverne

Take down policy

If you believe that this document breaches copyright please contact us at:

openaccess@tue.nl

providing details and we will investigate your claim. 


\title{
Coefficient of restitution for particles impacting on wet surfaces: An improved experimental approach
}

\author{
B. Crüger ${ }^{a}, *$, V. Salikov ${ }^{a}$, S. Heinrich ${ }^{a}$, S. Antonyuk ${ }^{b}$, V.S. Sutkar ${ }^{c}$, N.G. Deen ${ }^{c}$, \\ J.A.M. Kuipers ${ }^{c}$ \\ a Institute of Solids Process Engineering and Particle Technology, Hamburg University of Technology, Denickestrasse 15, 21073 Hamburg, Germany \\ b Particle Process Engineering, Department of Mechanical and Process Engineering, University of Kaiserslautern, Gottlieb-Daimler-Strasse, 67663 \\ Kaiserslautern, Germany \\ ${ }^{\mathrm{c}}$ Multiphase Reactors Group, Department of Chemical Engineering and Chemistry, Eindhoven University of Technology, P.O. Box 513, 5600 MB Eindhoven, \\ The Netherlands
}

\section{A R T I C L E I N F O}

\section{Article history:}

Received 3 December 2014

Received in revised form 10 April 2015

Accepted 14 April 2015

Available online 30 June 2015

\section{Keywords:}

Particle impact

Coefficient of restitution

Liquid layer

Improved experimental setup

\begin{abstract}
A B S T R A C T
The coefficient of restitution is widely used to characterize the energy dissipation rate in numerical simulations involving particle collisions. The challenge in measuring the coefficient of restitution is the strong scatter seen in experimental data that results from varying particle properties, i.e. shape and surface roughness, and from imperfections in the experimental technique. To minimize this scattering, a novel experimental setup was developed based on two synchronized high-speed cameras capturing the collision behaviour of a particle in three dimensions. To measure the wet restitution coefficient, which describes particle impact in the presence of a liquid layer in the contact region, additional accuracy can be achieved by measuring the liquid layer thickness by a high-precision optical confocal sensor. The coefficient of restitution was measured for glass particles with two different diameters, at different relative velocities and liquid layer thicknesses, with a focus on small collision velocities and thin liquid layers, using both the improved (three dimensional) and the conventional (two dimensional) approaches to quantify the improvement of the new method's accuracy.
\end{abstract}

(C) 2015 Chinese Society of Particuology and Institute of Process Engineering, Chinese Academy of Sciences. Published by Elsevier B.V. All rights reserved.

\section{Introduction}

Dynamic processes involving solids are widely used in various industries. For instance, in fluidized beds frequently used for drying, granulation, or agglomeration, particles interact with each other and the apparatus walls through a multitude of collisions. Depending on the process, these collisions happen under dry or wet conditions, which significantly influence energy transfer and dissipation during collisions. If the particles are wet beforehand, or are wetted during the process, additional energy losses within the liquid phase and mass transfer of the liquid between the collision partners take place. The energy losses during these collisions are important for proper modelling of particle dynamics and can be described by means of the coefficient of restitution (COR), e. The COR is defined as the ratio of the relative velocities of the colliding partners after and prior to impact, $v_{\mathrm{R}}$ and $v$, respectively. Thus, COR

\footnotetext{
* Corresponding author. Tel.: +49 4042878 3282; fax: +49 40428782678 .

E-mail address: britta.crueger@tuhh.de (B. Crüger).
}

depends on the dissipation of kinetic energy $\left(E_{\text {diss }}\right)$ during the complete collision (with $E_{\mathrm{kin}}$ and $E_{\mathrm{kin}, \mathrm{R}}$ as being kinetic energy before and after impact):

$e=\left|\frac{v_{\mathrm{R}}}{v}\right|=\sqrt{\frac{E_{\mathrm{kin}, \mathrm{R}}}{E_{\mathrm{kin}}}}=\sqrt{1-\frac{E_{\mathrm{diss}}}{E_{\mathrm{kin}}}}$.

The COR under dry conditions $\left(e_{\mathrm{dry}}\right)$ has been subject to extensive experimental and theoretical investigations (e.g. Antonyuk et al., 2010; Hastie, 2013; Kharaz, Gorham, \& Salman, 2001). In the dry case, energy dissipation depends mainly on the combination of materials and geometries of the contact partners. However, if liquid layers or droplets are present on the particle or wall surface, as happens in many processes, the COR $\left(e_{\text {wet }}\right)$ also depends on additional parameters, such as liquid properties, particle dimensions, and strongly on the collision velocity. These dependencies have not yet been fully investigated, especially in the range of small velocities and thin liquid layers, even though these are exactly the conditions present in many processes. For example, in a recent numerical investigation of a spouted bed by Salikov et al. (2015), the reported average inter-particle velocities range from 0.02 to 


\begin{tabular}{|c|c|}
\hline \multicolumn{2}{|c|}{ Nomenclature } \\
\hline$d_{50,3}$ & mean particle diameter, $\mathrm{m}$ \\
\hline$d_{\mathrm{P}}$ & particle diameter, $\mathrm{m}$ \\
\hline$e$ & coefficient of restitution \\
\hline$e_{\mathrm{dry}}$ & coefficient of restitution for dry collisions \\
\hline$e_{\text {wet }}$ & coefficient of restitution for wet collisions \\
\hline$E_{\text {diss }}$ & energy dissipation, $\mathrm{J}$ \\
\hline$E_{\mathrm{kin}}$ & kinetic energy, J \\
\hline$E_{\mathrm{kin}, \mathrm{R}}$ & kinetic rebound energy, $\mathrm{J}$ \\
\hline$h_{\text {conf }}$ & $\begin{array}{l}\text { liquid layer thickness measured by means of confo- } \\
\text { cal sensor, } m\end{array}$ \\
\hline$h_{\text {film }}$ & liquid layer thickness, m \\
\hline$h_{\text {mass }}$ & $\begin{array}{l}\text { liquid layer thickness measured by means of liquid } \\
\text { mass on target, } m\end{array}$ \\
\hline$m_{\mathrm{L}}$ & liquid mass on target, $\mathrm{kg}$ \\
\hline St & Stokes number \\
\hline$S t_{\mathrm{N}}$ & modified Stokes number \\
\hline$v$ & collision velocity, m/s \\
\hline$v_{\mathrm{R}}$ & rebound velocity, $\mathrm{m} / \mathrm{s}$ \\
\hline \multicolumn{2}{|c|}{ Greek symbols } \\
\hline$\sigma$ & standard deviation of measurement \\
\hline$\mu$ & mean value of measurement \\
\hline \multicolumn{2}{|c|}{ Acronyms } \\
\hline COR & coefficient of restitution \\
\hline CV & coefficient of variation \\
\hline SD & standard deviation \\
\hline
\end{tabular}

$0.2 \mathrm{~m} / \mathrm{s}$ in dependence on the apparatus zone. A numerical study by Fries, Antonyuk, Heinrich, Dopfer, and Palzer (2013) compared three different types of fluidized bed granulator configurations, namely a top-spray fluidized bed, a Wurster coater, and a prismatic spouted bed, and reported the particle-particle collision velocity for all three granulator types to be below $0.2 \mathrm{~m} / \mathrm{s}$. Additionally, the average particle-wall collision velocities remain below $0.3 \mathrm{~m} / \mathrm{s}$ for the Wurster coater, below $0.5 \mathrm{~m} / \mathrm{s}$ in the top-spray granulator, and below $0.7 \mathrm{~m} / \mathrm{s}$ in the spouted bed. In light of these observations, it seems especially important to investigate the coefficient of restitution for velocities below $1 \mathrm{~m} / \mathrm{s}$. However, the majority of research efforts (e.g. work of Antonyuk, Heinrich, Deen, \& Kuipers, 2009; Davis, Rager, \& Good, 2002; Dopfer et al., 2013; Kharaz et al., 2001; Montaine, Heckel, Kruelle, Schwager, \& Pöschel, 2011) have been executed at large collision velocities exceeding $1 \mathrm{~m} / \mathrm{s}$. To our knowledge, only Kantak, Galvin, Wildemuth, and Davis (2005) and Gollwitzer, Rehberg, Kruelle, and Huang (2012) have investigated smaller velocities, but there is still extended research that should be done in this field. Furthermore, because the liquid is usually introduced into the fluidized bed by means of a nozzle as fine ( $\mu \mathrm{m}$ sized) droplets, which spread to different degrees on the particle and wall surfaces, it is important to investigate the COR over a range of thin liquid layers.

Additionally, most previous reported measurements display large scatter within the experimental data (Antonyuk et al., 2009; Davis et al., 2002; Kantak et al., 2005). There are several sources for this scatter. On the one hand, energy dissipation is often caused by inelastic deformation or fracture of asperities on contacting surfaces (Montaine et al., 2011). The surface topology varies between particles but also in different contact areas within a single particle. This kind of scatter of the COR is thus natural and specific to a type and batch of particles. On the other hand, there are always errors produced by imperfect measurement techniques.
The objective of this paper is to introduce a novel experimental setup that can reduce those variations resulting from the method. For this aim, we further developed an experimental setup described by Antonyuk et al. (2009), which employs a high-speed camera to record the impact of single particles on a target plate. First, observation of the collision behaviour was extended to a third dimension by adding a second high-speed camera. As a second improvement, a non-stationary high-precision confocal sensor was used to measure the liquid layer thickness exactly at the impact area. Several experiments were conducted to quantify the improvement achieved by the applied changes. Additional measurements were performed with glass spheres of two diameters impacting on a glass plate, for different collision velocities and liquid layer thicknesses, with a focus on small velocities and thin liquid layers.

\section{Methodology}

\section{Experimental setup}

Fig. 1 schematically shows the experimental setup used in this work. Recording of the particle impacting and rebounding from the target is performed by means of two time-synchronized highspeed cameras (Y-4 and NX-4, Imaging Solutions, Eningen unter Achalm, Germany) with frame rates of $6000-8000 \mathrm{fps}$. One camera is positioned in front of the target to capture movement of the particle in the $x-y$ plane and the second is positioned above the target to record movement in the $x-z$ plane. Thus, particle movement can be observed in three dimensions, and the results can be verified by comparing the velocities in the $x$-direction obtained from both cameras. The target is mounted on an anti-vibration table and can be adjusted in the exact $x-y$ plane relative to the first camera by a positioning table. Furthermore, the target can be rotated to obtain a perfectly horizontal position, guaranteeing a uniform liquid layer. The target is bordered on the impact side by a $1 \mathrm{~cm}$ wide and approx. $200 \mu \mathrm{m}$ thick polymer ring to prevent liquid from running off.

The thickness of the liquid layer is measured at the exact impact area by an optical confocal sensor (Confocal DT IFS2405, MicroEpsilon, Ortenburg, Germany) with an error of less than $1 \mu \mathrm{m}$. The sensor is positioned above the impact point by means of a linear bearing and is translated away after the thickness measurement by a stepping motor. Simultaneously the particle, held at a predetermined height above the target by vacuum tweezers, is brought to the former position of the sensor. This is realized by mounting both the sensor and the tweezers' holders on the same linear bearing at a fixed distance from each other and by using a programmable motor for exact positioning. To avoid transfer of vibrations to the target during displacement, the linear bearing is fixed on an exterior frame with no mechanical connection to the anti-vibration table or the target plate. Directly after sensor displacement and particle positioning, the nozzle vacuum is released and the particle drops onto the target. The measurement area is illuminated from the front by two LED lamps $(1000 \mathrm{~lm})$ and from the back by a third LED lamp $(2700 \mathrm{~lm})$ which is positioned behind an opal glass to achieve diffuse lighting.

After the measurement, the coefficient of restitution is calculated according to Eq. (1) as a ratio of the mean rebound velocity after the liquid bridge has ruptured to the average velocity directly before the impact (Fig. 2). The particle velocities were obtained from image series by a MATLAB script.

\section{Materials}

Distilled water at $21^{\circ} \mathrm{C}$ with a layer thickness between 100 and $500 \mu \mathrm{m}$ was used as the liquid layer. The particles were glass beads (Type S, Swarco, Wattens, Austria) with mean diameters 


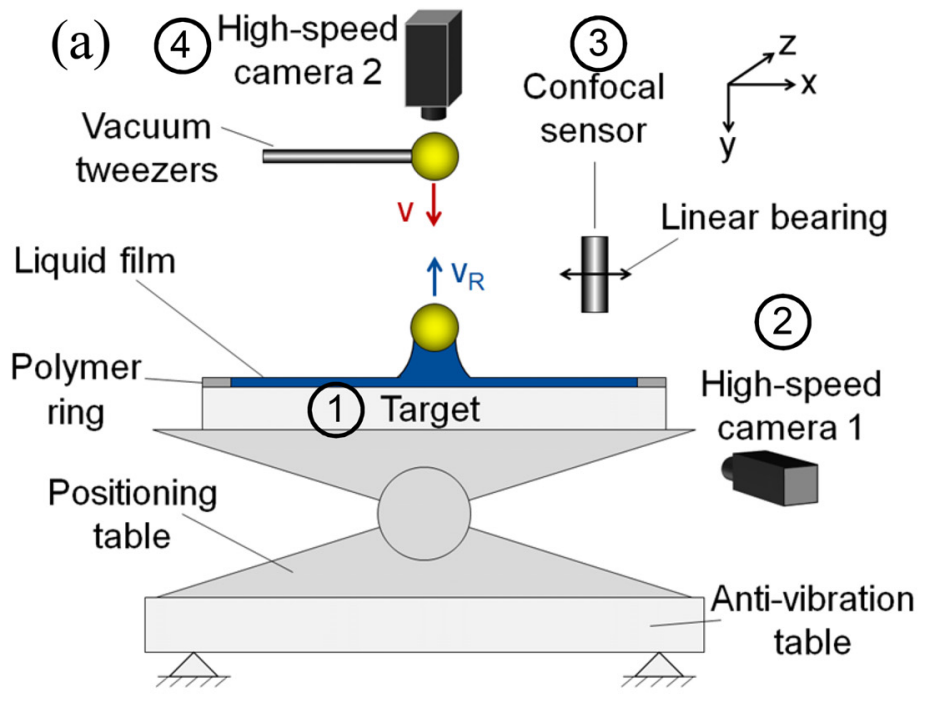

(b)
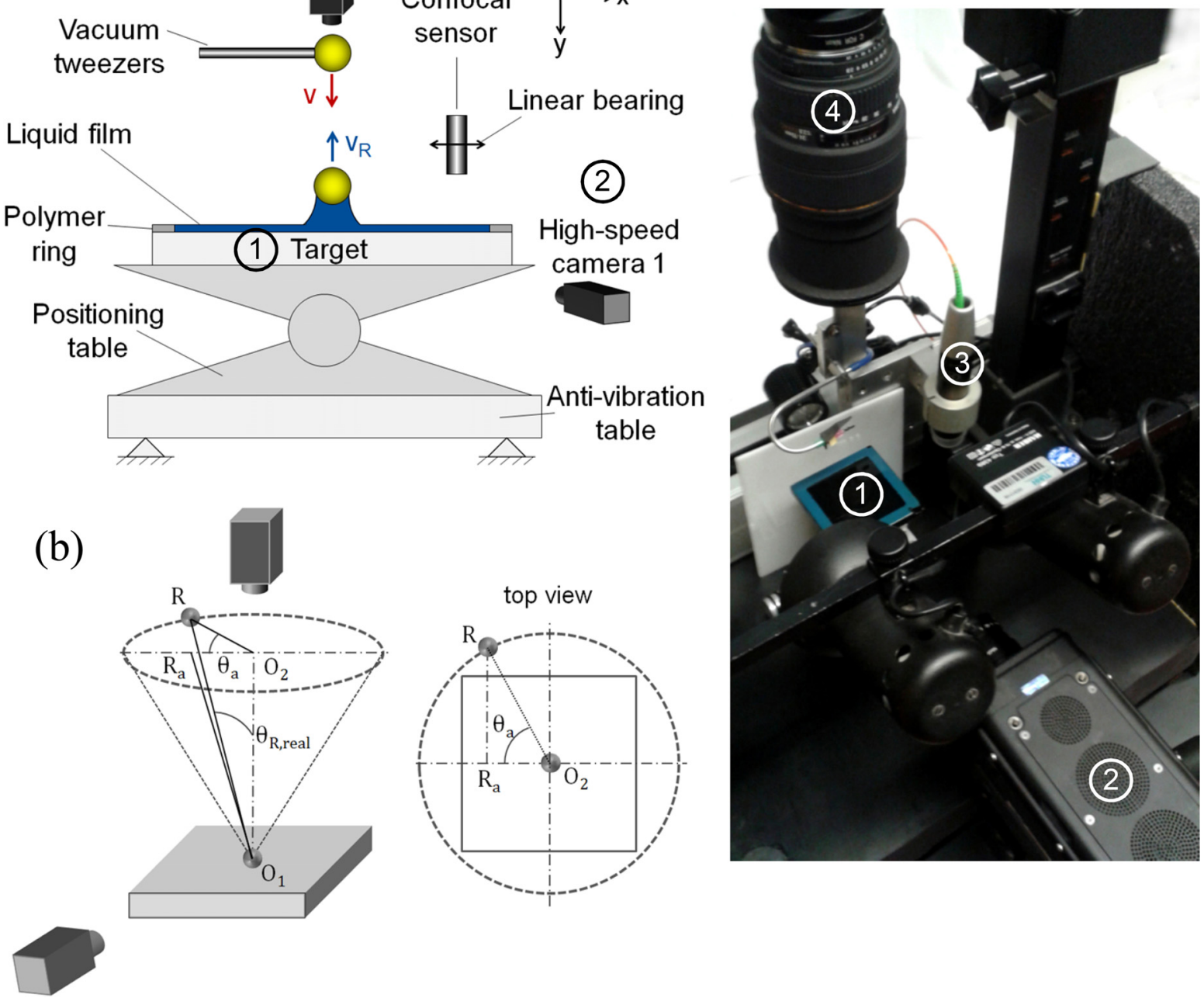

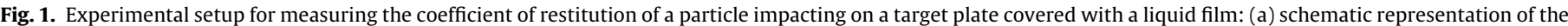

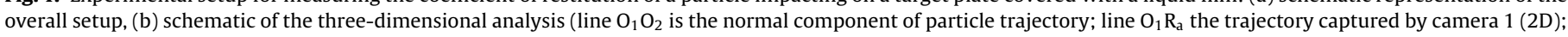
line $\mathrm{O}_{2} \mathrm{R}$ the trajectory captured by camera 2 ; line $\mathrm{O}_{1} \mathrm{R}$ the real trajectory (3D)), and (c) photo of actual setup.

$d_{50,3}$ of 0.91 and $1.74 \mathrm{~mm}$. The particles are closely sized, very spherical, and have almost no porosity (Fig. 3 ). The target was also a glass plate with $\mathrm{W} \times \mathrm{L} \times \mathrm{H}=80 \mathrm{~mm} \times 80 \mathrm{~mm} \times 10 \mathrm{~mm}$. To improve wetting, the target was first cleaned with $1 \mathrm{~N} \mathrm{NaOH}$ solution

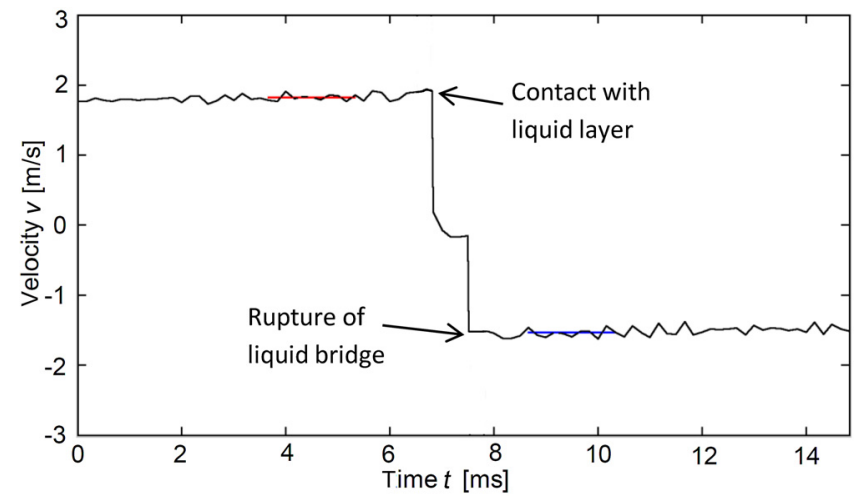

Fig. 2. Typical velocity-time plot for the impact and rebound of a $1.74-\mathrm{mm}$ particle colliding with a target covered with a 100 - $\mu \mathrm{m}$-thick liquid layer. Upper (red) and lower (blue) lines display the mean velocities before the impact and after the rupture of the liquid bridge, respectively. (For interpretation of the references to color in this figure legend, the reader is referred to the web version of this article.) and then carefully rinsed with distilled water and ethanol before each experimental series. Glass is a nearly ideal model material because it behaves dominantly elastic in the investigated range of impact velocities showing little dissipation of the collisional energy $\left(e_{\mathrm{dry}} \approx 0.96\right)$. Therefore the influence of the liquid can be assumed as the crucial source of energy dissipation and determines the coefficient of restitution in the experiments performed in this work.

\section{Results and discussion}

To test the previously described setup several experiments were conducted. First the improvements because of the second camera and the confocal sensor were investigated. Second the particle velocity, layer thickness, and particle diameters were varied for an exemplary parameter study and the experimental results were compared with several theoretical models available in literature.

\section{Improvements}

Despite a high sphericity, the used particles show small differences from the ideal shape and display surface irregularities (Figs. 3(b) and 4), which can lead to deviation from exactly vertical rebounds and rotation. To guarantee a normal impact, and enhance 

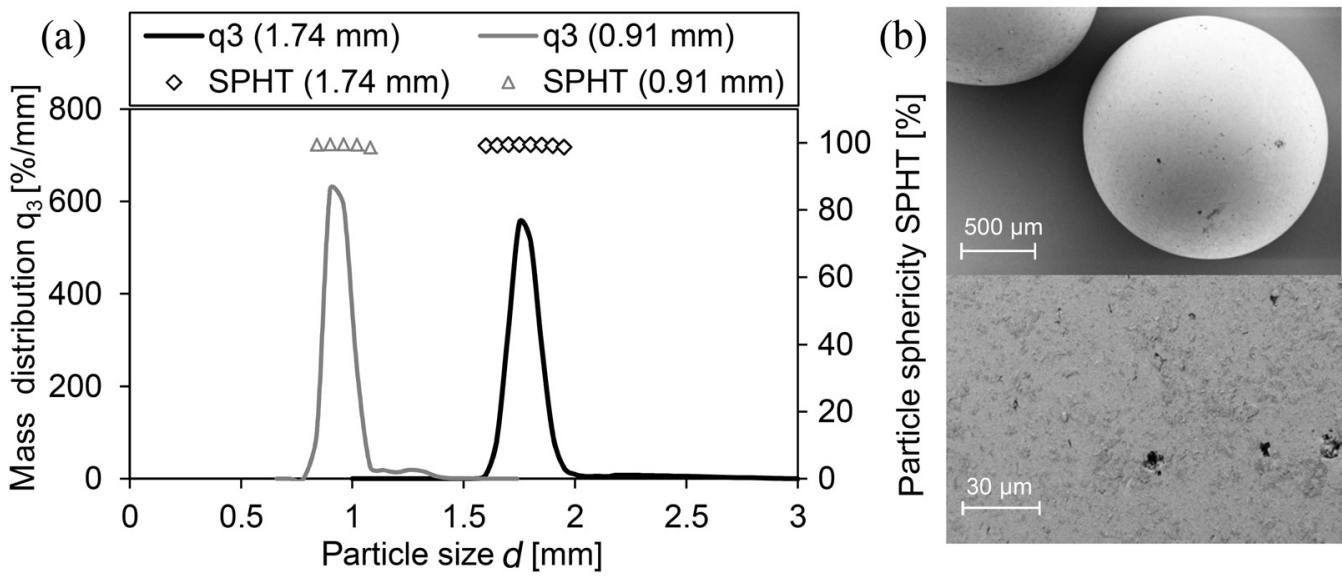

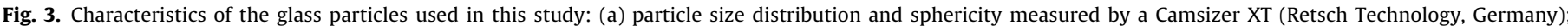
(b) SEM images with $100 \times$ and $2000 \times$ magnification.

accuracy of the results, an acceptance criterion has to be introduced. In our experiments, to be considered a successful measurement, a particle had to have a rebound angle from the vertical axis of less than $5.5^{\circ}$, as for angles below this value the influence of rebound angle on the COR was considered to be negligible. For each configuration, a mean COR and its standard deviation were calculated from 20 experiments. Fig. 4 shows a typical successful experiment, where a normal collision and rebound are guaranteed, since the particle does not move significantly in either $x$ - or $z$-directions, as can be seen in the images taken. On the contrary, in Fig. 5, a measurement is displayed that would be accepted in 2D measurements since impact and rebound appear to occur completely normally in the $x-y$ plane, but instead gets rejected in the 3D measurements because the rebound is oblique in the $z$-direction. In the shown case the main reason for the oblique rebound is deviation from ideal spherical particle shape.

\section{D high-speed image capturing}

To quantify the improvements in experimental results due to use of the second camera, the COR was obtained in two different ways and subsequently compared. The rebound angle is first measured using both cameras, which provides a 3D angle, and is also determined "as usual" by using only images from the front camera, which provides the $2 \mathrm{D}$ angle in the $x-y$ plane. For comparison, the standard deviation produced by both measuring techniques and the coefficient of variation (ratio of the standard deviation and the mean value) were calculated:

$\mathrm{CV}=\frac{\sigma\left(e_{\mathrm{wet}}\right)}{\mu\left(e_{\mathrm{wet}}\right)}$.

Fig. 6 shows the wet COR and corresponding standard deviations (SD) and coefficients of variation (CV) for the 3D and the 2D measurements of glass particles impacting the target covered with a $100-\mu \mathrm{m}$-thick water layer. The SD and CV of the 2D measurements are always higher than for the 3D measurements, especially at small collision velocities where the influence of the liquid film is greater. This can be explained by the influence of the rebound angle in the direction of the $z$-axis. If the particle rebounds partially into the $z$ - and/or $x$-directions, the rebound velocity and kinetic energy get split into normal and tangential components. Because, in 2D, the COR is calculated only by means of the velocities in the $y$-direction, the tangential part of the rebound velocity is not accounted for. This results in an estimated COR that is smaller than the actual one. By including the 3rd dimension ( $z$-direction) into the calculation of the rebound angle and using the aforementioned acceptance criterion, only the nearly straight rebounds are included within the results.
The disadvantage of this procedure, however, is the increased number of experiments required to achieve 20 successful results (for $e_{\text {wet }}$ approximately $50-100 \%$ more experiments compared to the $2 \mathrm{D}$ method with the same acceptance criterion). Nevertheless, the improved accuracy should compensate for this disadvantage as a SD of $20 \%$ of the mean is too high to determine whether colliding particles stick or rebound at low collision velocities (Fig. 6(b)).

\section{Layer thickness}

The second improvement of the setup is the application of a confocal sensor using chromatic light to measure the distance or thickness of transparent media. The liquid layer thickness could be measured directly in the area where the particles will impact by moving the sensor to the exact spot and removing it again after the thickness measurement. Usually, the weighing method is used to determine the liquid mass (volume) and the layer thickness (Antonyuk et al., 2009; Davis et al., 2002; Kantak et al., 2005). To quantify the improvements from measuring the layer thickness by the confocal sensor, we compared our measurements to the thickness calculated from the mass of water on the target, using a high precision balance. The results are displayed in Table 1.

The measured thicknesses for the $200-\mu \mathrm{m}$ film agree quite well, because the approx. $200-\mu$ m-thick polymer ring helps to form a uniform liquid layer. For thinner and thicker films, however, the calculations differ strongly from the measured values. The surface tension of the liquid results in an uneven film surface, which is concave for liquid films thinner than the polymer ring (liquid-solid contact on vertical part of ring) and convex for larger film thicknesses (liquid-solid contact on the horizontal surface of the polymer ring). Therefore, the film thickness averaged over the liquid film calculated from the liquid mass is higher for thin films and smaller for thick films than the actual thickness measured by the confocal sensor at the impact area in the middle of the target. This error in film thickness determination from liquid mass will also appear without the polymer ring, because a liquid profile will still manifest even in this case. Therefore, if no direct measurement

Table 1

Comparison of the liquid film thickness measured by the confocal sensor and calculated by means of the liquid mass.

\begin{tabular}{llll}
\hline$h_{\text {conf }}(\mu \mathrm{m})$ & $m_{\mathrm{L}}(\mathrm{g})$ & $h_{\text {mass }}(\mu \mathrm{m})$ & $\begin{array}{l}\text { Relative deviation } \\
f(\%)\end{array}$ \\
\hline 100 & $0.403 \pm 0.012$ & 161 & 61 \\
200 & $0.730 \pm 0.014$ & 203 & 1.5 \\
300 & $1.045 \pm 0.009$ & 290 & -3.2 \\
500 & $1.657 \pm 0.003$ & 460 & -7.9 \\
\hline
\end{tabular}



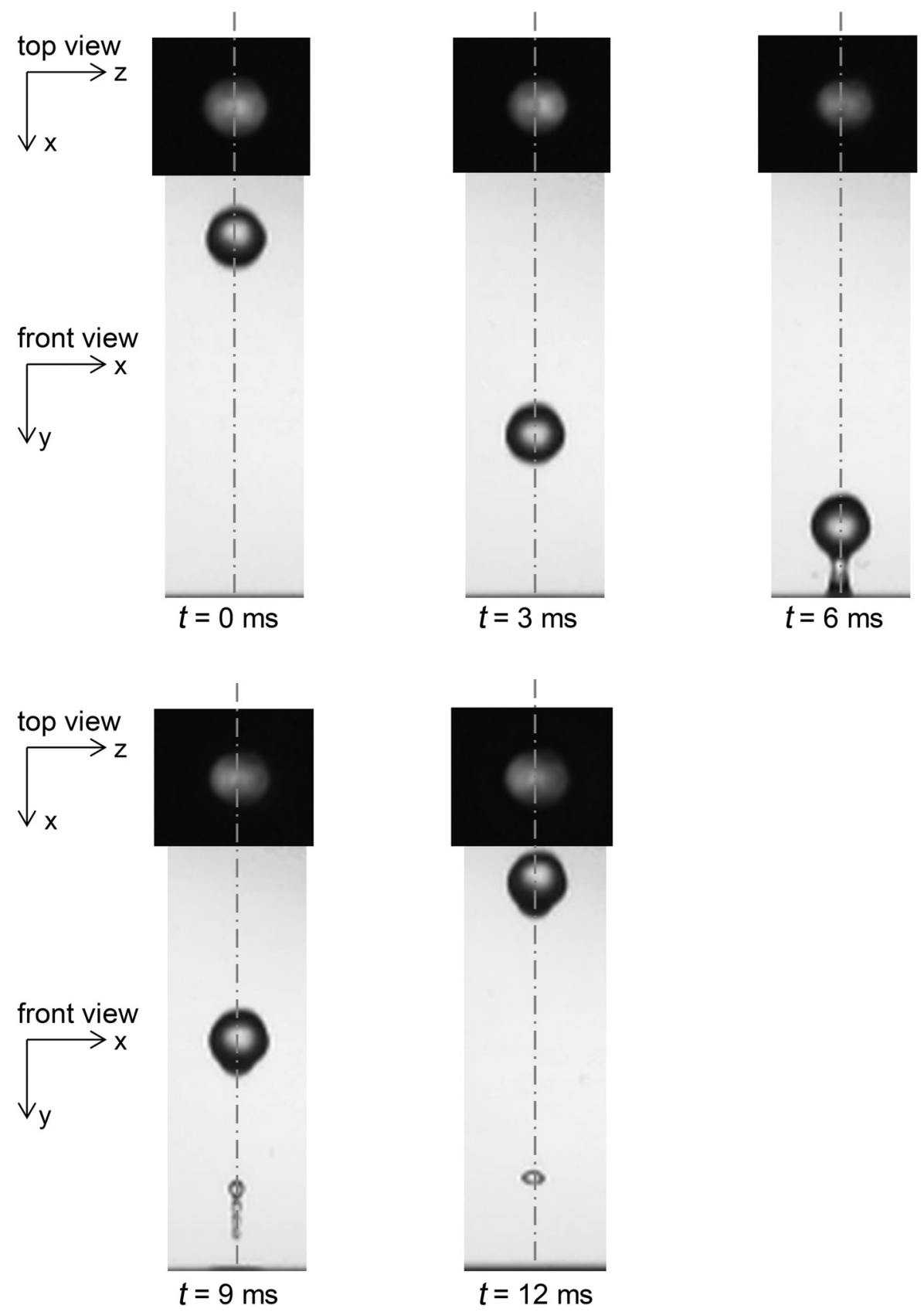

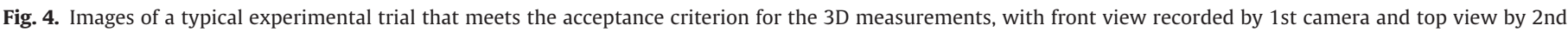
camera. Times $t=0-3 \mathrm{~ms}$ represent the impact (downward movement) and $t=6-12 \mathrm{~ms}$ the rebound (upward movement) of the particle.

is used it would be better to apply a polymer ring with the same thickness as of the desired liquid film for each experiment, since the thickness of the film has a large influence on the COR, as has already been shown by different authors (Antonyuk et al., 2009; Gollwitzer et al., 2012) and which can also be seen from results of this work, presented in the following section.

\section{Measurements of the normal coefficient of restitution}

With the improved setup, the coefficient of restitution was measured for glass spheres with mean diameters of 0.91 and $1.74 \mathrm{~mm}$ at impact velocities ranging from 0.2 to $1.9 \mathrm{~m} / \mathrm{s}$ and a liquid layer thickness between 100 and $500 \mu \mathrm{m}$. The obtained 3D-results are shown in Fig. 7. For the dry case, the COR is nearly independent of the particle size and velocity over the examined range. But the addition of a small amount of water (films of only $100-\mu \mathrm{m}$ thickness) has a considerable effect. For collision velocities smaller than a certain value, the so-called sticking velocity, the particles stick to the film after impact, leading to $e=0$. The sticking velocity depends on the film thickness (Fig. 7(b)) and particle size (Fig. 7(c)). With increasing layer thickness the sticking velocity increases (Fig. 7(a)), because viscous damping by the liquid layer increases. If the velocity is increased above the sticking point, the COR increases steeply towards a constant value within the examined range, that approaches the value for dry conditions, but remains smaller than the "dry" COR (Fig. 7(a and c)). For each particle velocity there also exists a critical film thickness, above which the particle sticks to the liquid, as can be seen in Fig. 7(b) for two velocities, e.g. for $0.55 \mathrm{~m} / \mathrm{s}$, the particle sticks to the liquid if the film thickness exceeds $500 \mu \mathrm{m}$. This observation validates the results in (Antonyuk et al., 2009; Dopfer et al., 2013), where similar behaviour was found. 

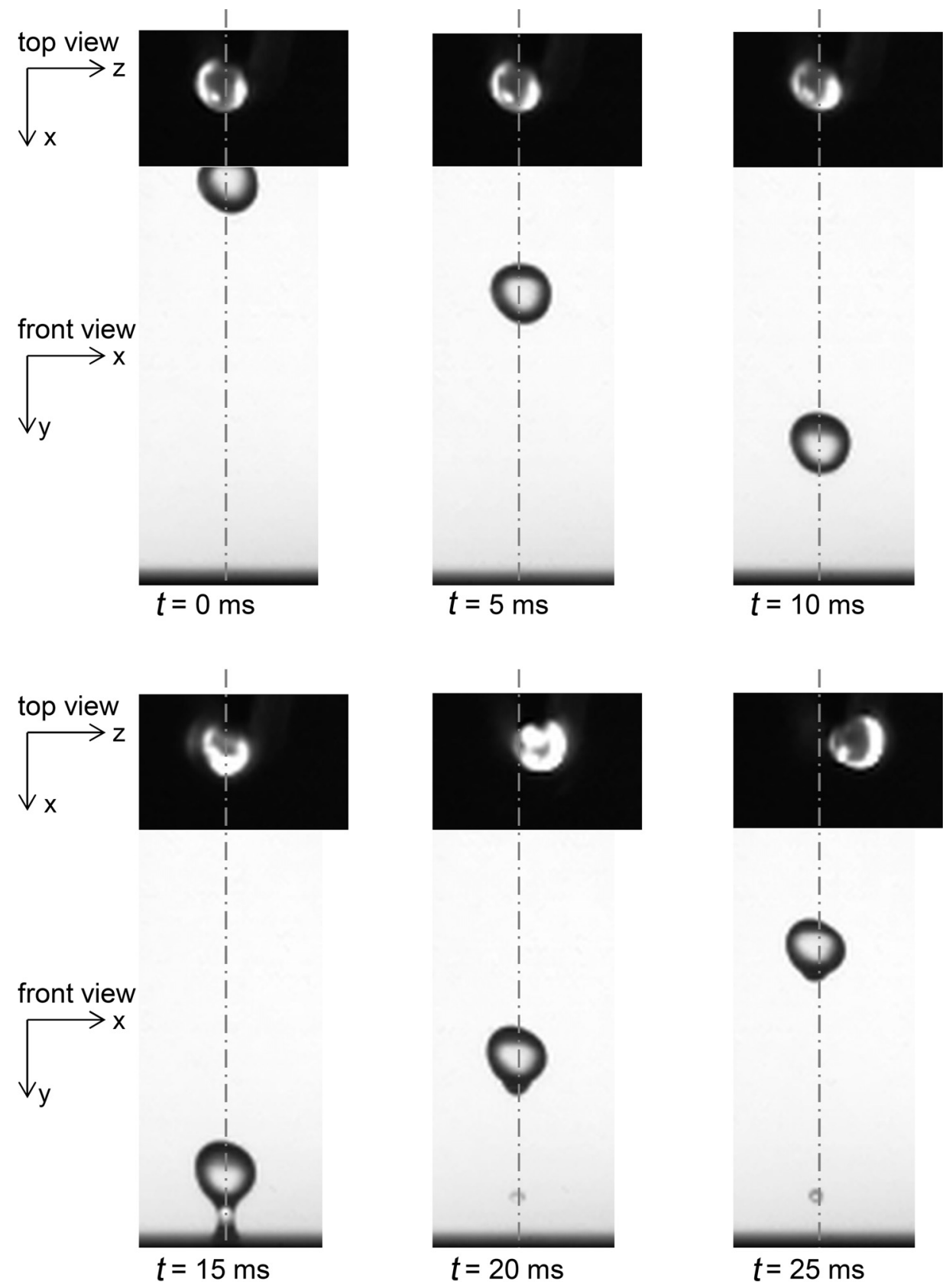

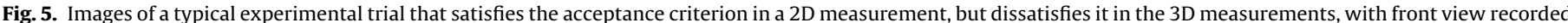

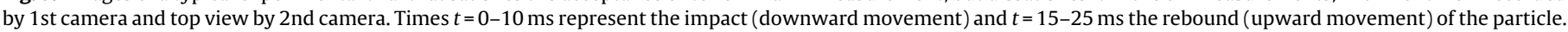

Additional experiments were conducted using glass particles with a smaller diameter of $0.91 \mathrm{~mm}$, to analyze the influence of particle size on the COR. Fig. 7(c) compares the results of the two particle sizes, showing that for dry collisions the COR is independent of the particle size. For smaller particles impacting on the target covered with films of the same thickness the COR decreases with decreasing particle diameter, whereas the general trends with collision velocity are similar. The sticking velocity increases, because the fraction of the particle surface that is in contact with the liquid increases with decreasing particle diameter (mass-specific surface area), which leads to a higher influence of viscous damping, and ultimately results in a smaller COR.

Antonyuk et al. (2009) developed a detailed model for the prediction of the COR based on a force balance, which was compared to the experimental results of this work in Fig. 8. The model shows good qualitative agreement with the experimental data from this work. The influence of thin liquid layers and small particle diameters $\left(d_{50,3}=0.91 \mathrm{~mm}\right)$ is especially well represented (Fig. 8(a)). However, the sticking point could not be properly predicted by the model of Antonyuk et al. except for the small particle diameter and thinnest $(100 \mu \mathrm{m})$ liquid layer. For increasing layer thickness as well as for increasing collision velocities the model gets less accurate and overestimates the actual COR. Therefore, the force model of Antonyuk et al. still needs some adjustments to be able to predict the COR for wet collisions over a range of parameters. Because some of the equations for forces used in the model are based on various simplifications, these deviations could be reduced by applying more exact equations for the single forces.

Another model often cited is the elastohydrodynamic model by Davis et al. (2002). In that work an equation was introduced 


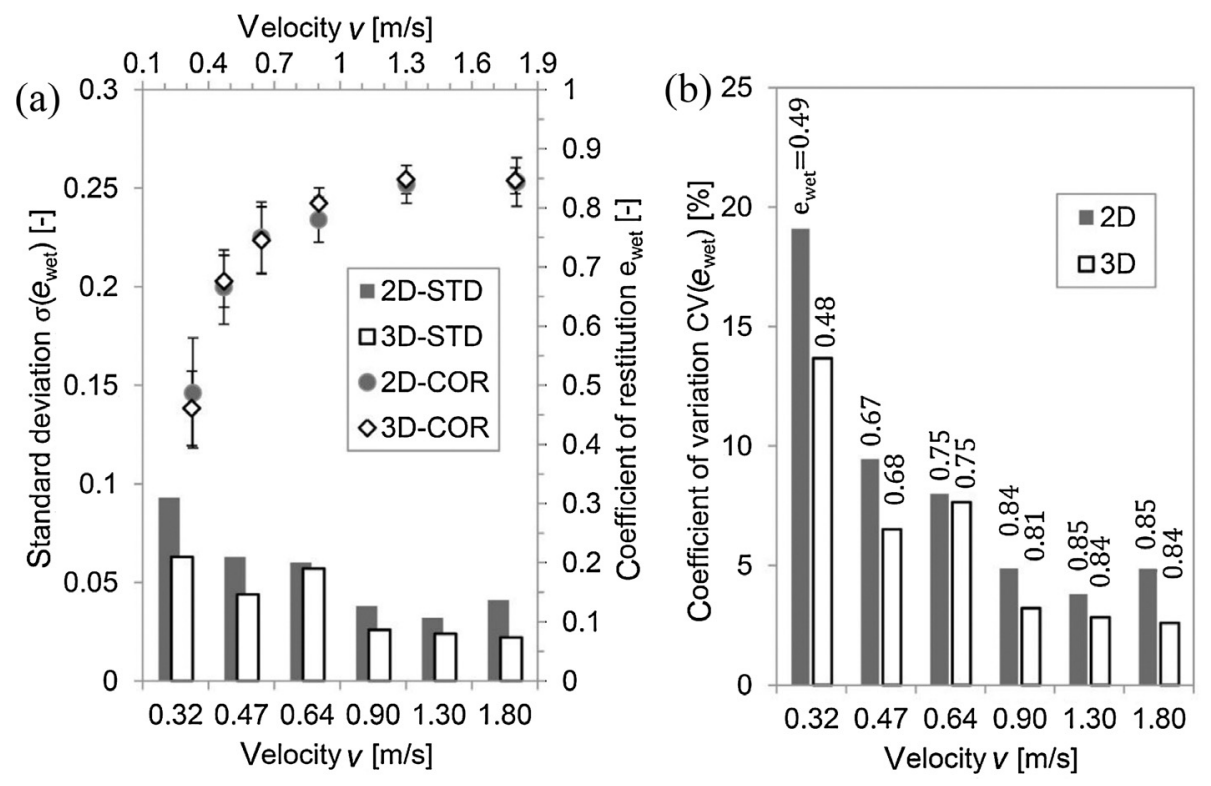

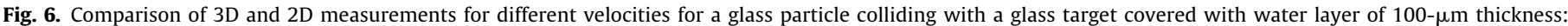
(a) standard deviations and coefficients of restitution, (b) coefficient of variation.
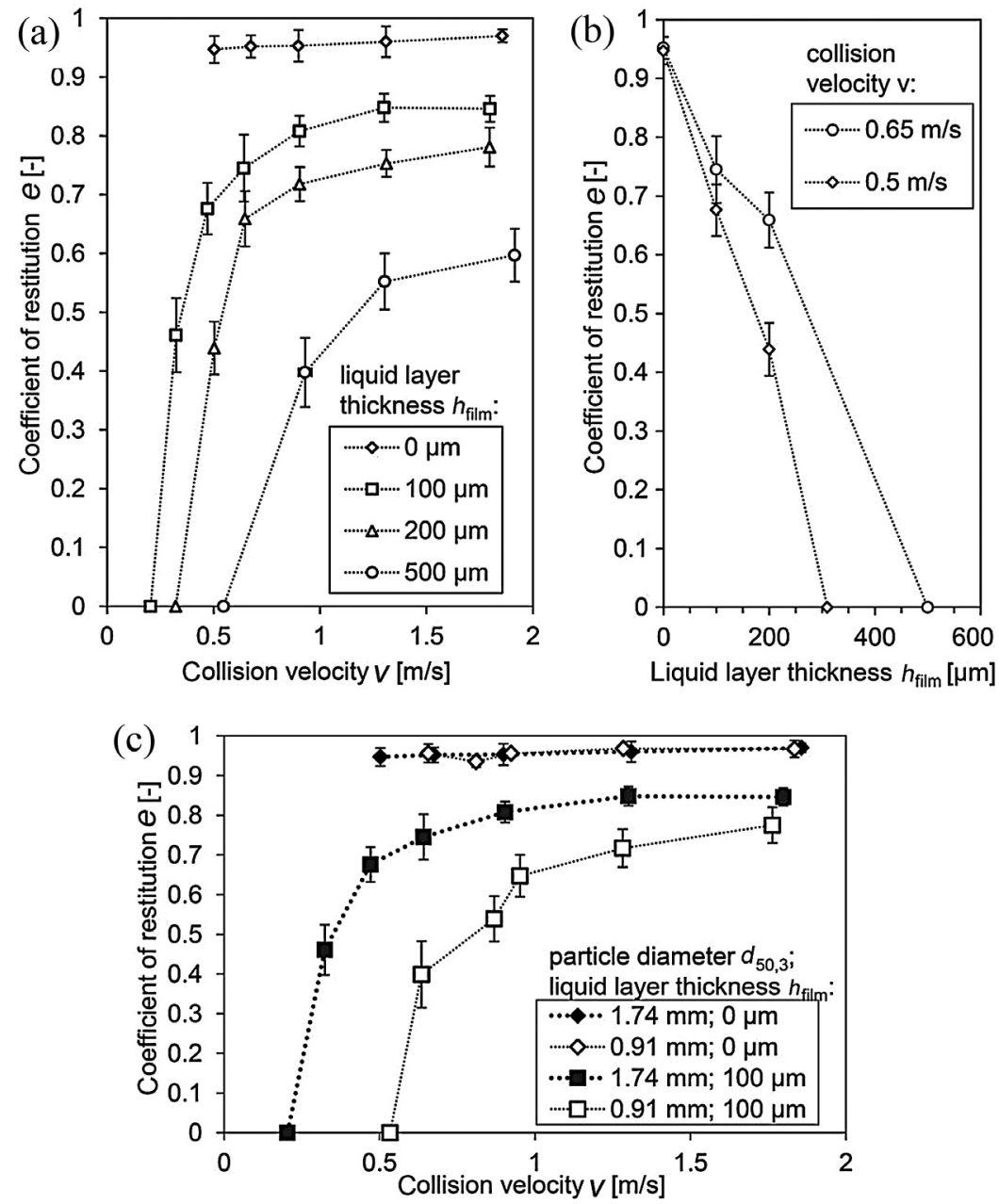

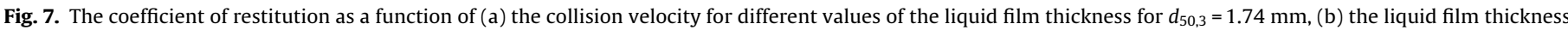
for different velocities for $d_{50,3}=1.74 \mathrm{~mm}$, and (c) a comparison of the dependence of the coefficient of restitution on the collision velocity for different particle sizes. 


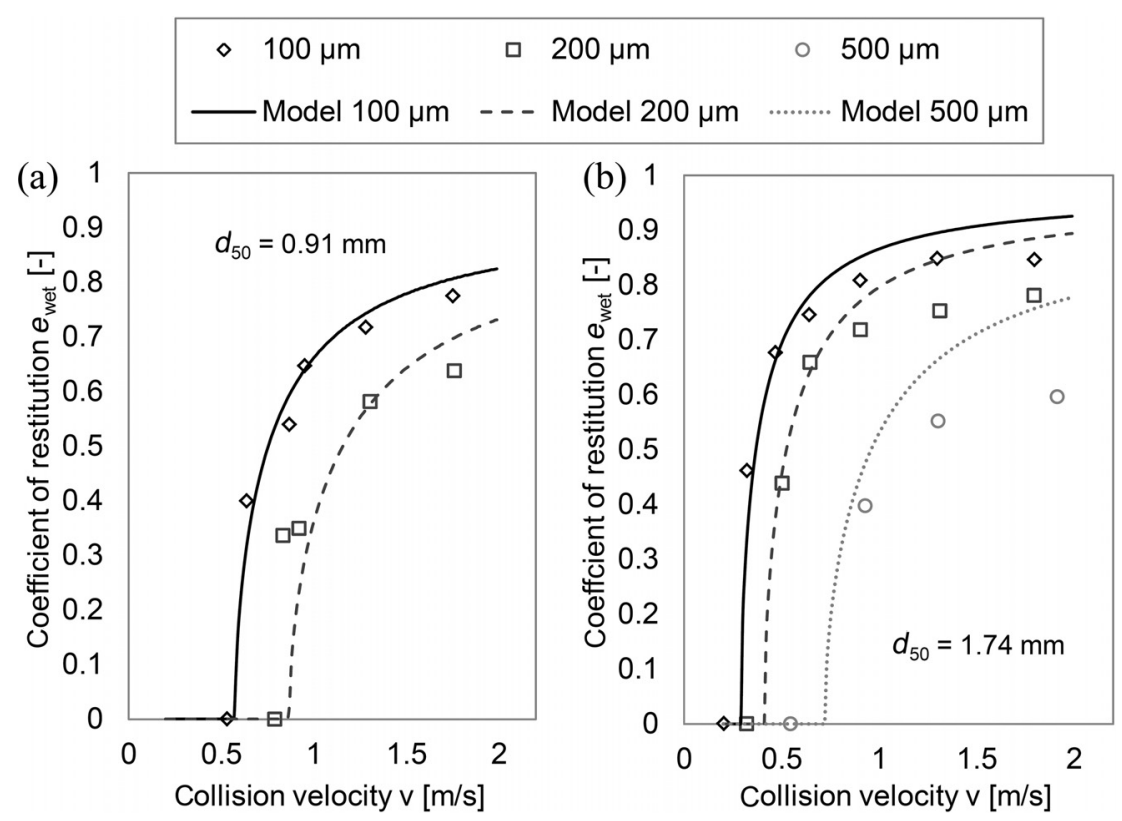

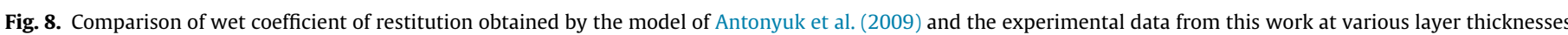
for (a) particles with $d_{50,3}=0.91 \mathrm{~mm}$, (b) particles with $d_{50,3}=1.74 \mathrm{~mm}$.

that links the effective wet COR with the Stokes number St, characteristic for the collision:

$e_{\text {wet }}=e_{\text {dry }}\left(1-\frac{S t_{c}}{S t}\right), \quad S t>S t_{c}$,

with

$S t=\frac{m v_{0}}{6 \pi \eta R^{2}}$.

The COR for the dry collision (which can be measured rather easily and is often approximately constant) and a critical Stokes number $S t_{c}$ are used as parameters within this model. $S t_{c}$ can be measured as the value when the particle sticks to the liquid layer or it can be calculated by different empiric equations.

Fig. 9(a) shows a comparison between the Davis et al. (2002) model and experimental results obtained in this work. At higher liquid layer thicknesses and small Stokes numbers the model can predict the COR quite well, but for smaller layer thicknesses, the steep increase of the COR in the range of small Stokes numbers is underestimated, whereas values for higher Stokes numbers are overestimated. The model constructed by Davis et al. (2002) depicts the correct sticking point for each case, because the sticking point is one of the input parameters.

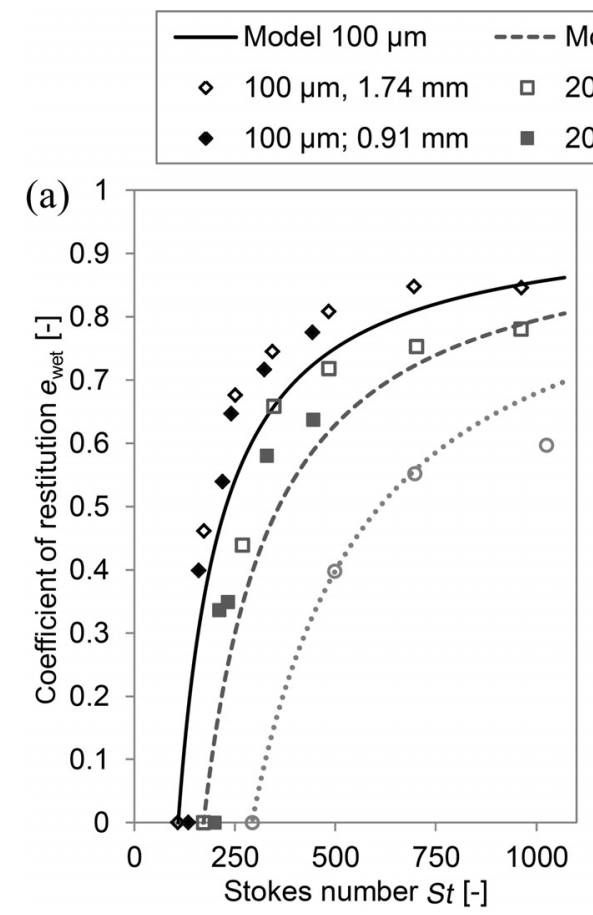

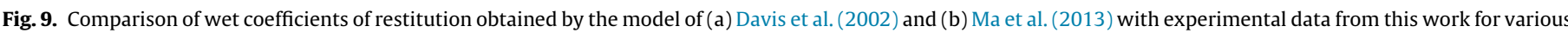
layer thicknesses and particle sizes. 
The necessity to measure the sticking parameter for each layer thickness is the major disadvantage of the Davis et al. model. Therefore, Ma, Liu, and Chen (2013) suggested a modified Stokes number, $S t_{N}$, which includes the layer thickness:

$S t_{\mathrm{N}}=\frac{m v_{0}}{\eta h_{\text {film }} d_{\mathrm{P}}}$.

Thus the experimental results for different layer thicknesses should coincide in one line. Fig. 9(b) indicates a good agreement between this model and the experiments with only minor overestimation of the COR for high values of the modified Stokes number $S t_{N}$ (high collision velocities and small layer thicknesses).

\section{Conclusions}

The main goal of this work was to develop a method to accurately measure the restitution coefficient. To achieve this goal, the experimental setup of Antonyuk et al. (2009) was redesigned and complemented by incorporating a second high-speed camera and a confocal sensor to improve the measurement quality. The application of two cameras allows a 3-dimensional observation of the collision event and leads to much smaller standard deviations compared with the generally used 2-dimensional method, particularly in the range of low impact velocities. The confocal sensor allows for precise measurement of the liquid layer thickness rather than calculating it from the liquid mass. The sensor was made to be moveable, which allowed the layer thickness to be measured at the exact area of impact. A significant deviation of the layer thickness at the impact area from the calculated one was found, especially for thin layers. Thus the strongest improvements by the presented technique in the measurement accuracy concern regions of low particle velocities and small liquid layer thickness, which are also often the prevailing conditions in fluidized or spouted beds. The energy dissipation during collisions of single particles in the presence of liquid layers was investigated for different values of the layer thickness (100-500 $\mu \mathrm{m})$, different collision velocities, and different particle sizes. All three investigated parameters show strong influence on the COR. For velocities lower than a sticking velocity, and for liquid films higher than a critical film thickness, the particle sticks to the liquid film leading to a COR of zero. The experimental results were compared with three models for the wet COR from the literature. Qualitative good agreement of the models is shown, but the quantitative accuracy has still to be improved. In the investigated parameter range, the best agreement was obtained by the model of Ma et al. (2013).

\section{Acknowledgements}

We gratefully acknowledge financial support from the German Research Foundation (DFG), Germany, and Technology Foundation STW, The Netherlands, via project number HE 4526/9-1, and from the German Research Foundation (DFG) via SFB 986 " $\mathrm{M}^{3}$ ", project A3 and A6.

\section{References}

Antonyuk, S., Heinrich, S., Deen, N., \& Kuipers, H. (2009). Influence of liquid layers on energy absorption during particle impact. Particuology, 7, 245-259.

Antonyuk, S., Heinrich, S., Tomas, J., Deen, N. G., van Buijtenen, M. S., \& Kuipers, J. A. M. (2010). Energy absorption during compression and impact of dry elastic-plastic spherical granules. Granular Matter, 12, 15-47.

Davis, R. H., Rager, D. A., \& Good, B. T. (2002). Elastohydrodynamic rebound of spheres from coated surfaces. Journal of Fluid Mechanics, 468, 107-119.

Dopfer, D., Palzer, S., Heinrich, S., Fries, L., Antonyuk, S., Haider, C., et al. (2013). Adhesion mechanisms between water soluble particles. Powder Technology, 238, 35-49.

Fries, L., Antonyuk, S., Heinrich, S., Dopfer, D., \& Palzer, S. (2013). Collision dynamics in fluidised bed granulators: A DEM-CFD study. Chemical Engineering Science, 86, $108-123$.

Gollwitzer, F., Rehberg, I., Kruelle, C., \& Huang, K. (2012). Coefficient of restitution for wet particles. Physical Review E, 86(1), 011303.

Hastie, D. B. (2013). Experimental measurement of the coefficient of restitution of irregular shaped particles impacting on horizontal surfaces. Chemical Engineering Science, 101, 828-836.

Kantak, A. A., Galvin, J. E., Wildemuth, D. J., \& Davis, R. H. (2005). Low-velocity collisions of particles with a dry or wet wall. Microgravity Science and Technology, 17(1), 18-25.

Kharaz, A. H., Gorham, D. A., \& Salman, A. D. (2001). An experimental study of the elastic rebound of spheres. Powder Technology, 120, 281-291.

Ma, J., Liu, D., \& Chen, X. (2013). Experimental study of oblique impact between dry spheres and liquid layers. Physical Review E, 88(3), 033018.

Montaine, M., Heckel, M., Kruelle, C., Schwager, T., \& Pöschel, T. (2011). The coefficient of restitution as a fluctuating quantity. Physical Review E, 84(4), 041306.

Salikov, V., Antonyuk, S., Heinrich, S., Sutkar, V. S., Deen, N. G., \& Kuipers, J. A. M. (2015). Characterization and CFD-DEM modelling of a prismatic spouted bed. Powder Technology, 270, 622-636. 